\title{
Journal of Phylogenetics \& Evolutionary Biology
}

\section{Primary Succession Recapitulates Phylogeny}

\section{Felix Bast}

Centre for Plant Sciences, Central University of Punjab, Bathinda, Punjab, India

"Corresponding author: Felix Bast, Centre for Plant Sciences, Central University of Punjab, Bathinda, Punjab, India, Tel: +91 98721 52694; E-mail: felix.bast@gmail.com

Received date: January 04, 2016; Accepted date: January 06, 2016; Published date: January 12, 2016

Copyright: (c) 2016 Bast F. This is an open-access article distributed under the terms of the Creative Commons Attribution License, which permits unrestricted use, distribution, and reproduction in any medium, provided the original author and source are credited.

\begin{abstract}
The parallelism between the process of primary succession and the evolution of life on this planet is remarkable and conspicuous, yet never been spotted before. The order, at which each seral community appear, right from the pioneer species until the climax communities, is by the order of appearance of the respective evolutionary lineages in the tree of life. Evolutionary history of life on this planet is, in fact, a massive and ongoing process of primary succession, and I believe that is the rationale for this striking harmony. Central premise of this postulation is the idea that the plants that have been evolved to adapt to an almost naked landscape would be the first to colonize new environments. In light of this parallelism, fields of ecological succession and phylogenetic systematics can mutually compliment for resolving perplexed conundrums, and can potentially enlighten the future of life on the planet earth.
\end{abstract}

Keywords: Abiogenesis; Earth; Evolution; Exobiology; Life; Phylogenetics; Pioneer species; Sere

\section{Editorial}

Ernst Haeckel's pithy aphorism "ontogeny recapitulates phylogeny," alternately referred as the recapitulation theory, biogenetic law or theory of embryonic parallelism, has been one of the pivotal observations in biology that integrated disciplines of evolutionary biology and developmental biology to the portmanteau field EvoDevo. Haeckel's observation was indeed simple; successive stages in the organism's early (embryonic) development remarkably, albeit figuratively and metaphorically, reflect adult stages in the evolutionary history of respective species, and therefore he surmised the parallelism between ontogeny and phylogeny as interesting. While the recapitulation theory has largely been discredited in modern biology to an extent to refer it defunct, successional stages of embryos do reflect stages in the phylogeny, albeit the correspondence being vestigial and rudimentary. One reason for the downright discredit of recapitulation theory had been its incorrect interpretation as an advocacy of Lamarckian straight-line evolution (orthogenesis), and digression from Darwinian Theory [1]. However, Haeckel resorted to Lamarck only to accentuate the parallelism, not to refute the theory of common descent; he had been a resolute Darwinist throughout his life, winning the prestigious Darwin-Wallace Medal in 1908. More importantly, recapitulation theory was reported by many racists (list include legendries, such as William Blake, and Rudyard Kipling) in $19^{\text {th }}$ and $20^{\text {th }}$ centuries to upheld the so-called "primitive-as-child" argument, interpreting it erroneously as a proof for scientific racism. In addition, this theory had been wrongly paraphrased in countless humanity disciplines; for example criminal anthropology, literature, literary criticism, aesthetic sensibility, and even in most of the Freudian psychoanalysis, as articulated in masterly rhetoric by Stephen Jay Gould (Gould's Freud's Evo Fantasy) (Gould's Ontogeny Recapitulates Phylogeny).

Succession is a central topic in ecology that captures the dynamic attributes of plant communities. The basic premise is quite straightforward; temporal changes in the plant community structure of a particular locality are in an orderly manner. Clements [2] who is regarded as the founder of the discipline of succession-regarded plant communities as giant organisms. He coined the term "primary succession" to refer changes in undisturbed community structure beginning on the lifeless land with no soil present. On the other hand, secondary succession, described first by Gleason [3], embark on when a natural community is disturbed (for instance, aftermath of forest fire), but soil and seed stock remains.

When I first came across the topic of ecological succession, a parallelism between primary succession (albeit not the secondary succession) and the phylogeny became conspicuous; seral communities passes through successive stages that remarkably reflect stages in the evolutionary history of the lineages of the comprising species with which these communities are formed of. In my knowledge, no one has ever described this parallelism, despite it being as coherent as the full moon in a clear sky. Considering that no two extant species have been evolved from one another, this postulation is not about the species itself, but its "lineages" (phylogeny). For example, Sousa [4] demonstrated that green algal genus Ulva appear first and perennial red alga such as Gigartina appear last in his experiment to trace primary succession of seaweed communities on concrete boulders kept at intertidal habitat, Ellwood Beach, California. If probability of having such a successional pattern across other places in the world is statistically significant, this could potentially indicate that chlorophyceans (rather than genus Ulva) appearing anterior to rhodophyceans (rather than genus Gigartina) in time-calibrated tree of life- a topic of considerable debate in algal phylogenetic systematics. Fossils of red algae Bangiomorpha had been discovered from arctic Canada that is 1.2 billion years old, making them oldest known fossils of any Eukaryotes. However, the absence of described fossils that old of green algae cannot render our earlier proposition that green algae being older than red algae invalid. Fossil evidence, however convincing it may, is widely discontinuous due to a multitude of factors such as differential rate of fossilization. The case might merely that the fossils of green algae older than Bangiomorpha are to be discovered. 
Page 2 of 2

Primary succession begins with a pioneer species -that establishes first in the lifeless substratum- characterized by r-selected species such as bacteria, algae, and mosses. Pioneer community transforms itself to successive intermediate successional stages (seres). The final seral stage, sometimes referred as climax community, is characterized by Kselected species, such as hardwood trees. These orderly stages remarkably reverberate evolutionary history of the lineages of these species itself; for instance bacteria to algae to mosses to ferns to spermatophytes.

I believe the cardinal reason for this surprising consonance between primary succession and phylogeny is that the entire evolutionary history of life on earth can be viewed as a colossal and incessant process of primary succession. Eubacteria might have been the pioneer species of earth's early evolutionary history. Each successive communities of organisms, be it cyanobacteria, protists, archeplastidans, or chromistans, are seral stages of increasing complexity. In this progression, earlier seres in fact coexist with the newer seres, not being replaced with.

The potential impact of this parallelism is phenomenal. It might even be possible to reconstruct the past seres, or predict the future seres, by phylogenetic analysis of the species involved. Contrasting models of ecological succession, such as climax-pattern model, facilitation model, inhibition model, tolerance model, etc., can be used to refine models of phylogenetics, and vice versa. The analogy between the evolution of life on earth and primary succession can enlighten an array of conundrums on both fields. For example, amongst contrasting species, which species originated first in the tree of life (for instance, Cycads, Ginkgos or Conifers). Conversely, as shade intolerant trees appear anterior to the shade tolerant trees in forest succession, the character state "shade tolerance" might be a derived state (apomorphy). Likewise, we may also infer that $\mathrm{r}$-selected species are evolutionarily more primitive than K-selected species.
Lastly, it is now understood that those species that appear first in ecological succession (i.e., pioneer species) also disappear last, and those species that appear last in ecological succession (i.e., climax species), also disappear first (Sousa) [4]. If we interpret tree of life in light of the parallelism propounded in this write-up, we may postulate that species such as eubacteria that appeared first on the tree of life would be the one that disappears last, and species such as human beings that appeared last would be the first to disappear, an argument that corroborates "Oreo Model" [5,6], with multicellular "cream" sandwiched between two prokaryotic "cookies".

\section{Acknowledgement}

I thank Department of Science and Technology, Govt. of India for supporting this study partly in form of DST-INSPIRE faculty award (IFA11-LSPA02).

\section{References:}

1. Richards RJ (2008) The tragic sense of life: Ernst Haeckel and the struggle over evolutionary thought. University of Chicago Press, Chicago.

2. Clements FC (1916) Plant succession: an analysis of the development of vegetation. Carnegie Institution of Washington,

3. Gleason HA (1926) The individualistic concept of the plant association. Bulletin of the Torrey Botanical Club 53: 7-26.

4. Sousa WP (1979) Experimental investigations of disturbance and ecological succession in a rocky intertidal algal community. Ecological monographs 49: 227-254.

5. Caldeira K, Kasting JF (1992) The life span of the biosphere revisited. Nature 360: 721-723.

6. O'Malley-James JT, Greaves JS, Raven JA, Cockell CS (2013) Swansong biospheres: refuges for life and novel microbial biospheres on terrestrial planets near the end of their habitable lifetimes. International Journal of Astrobiology 12: 99-112. 